\title{
PEMODELAN GEOLOGI BAWAH PERMUKAAN BANTAR KARET, JAWA BARAT MENGGUNAKAN METODE GRAVITASI
}

\author{
Jamaluddin $^{1 *}$ Maria $^{2}$, Hamriani Ryka ${ }^{1}$, Rohima Sera Afifah ${ }^{1}$ \\ ${ }^{1}$ Program Studi Teknik Geologi, STT-Migas Balikpapan, Indonesia. \\ ${ }^{2}$ Departemen Geofisika, Fakultas Matematika dan Ilmu Pengetahuan Alam, Universitas Hasanuddin, Makassar, \\ Indonesia \\ *Penulis koresponden. Alamat email: jamaluddin@sttmigas.ac.id
}

\begin{abstract}
Abstrak
Metode gravitasi merupakan salah satu metode geofisika yang sering digunakan untuk mendapatkan informasi tentang gambaran bawah permukaan melalui perbedaan rapat massa antar batuan di sekitarnya. Data anomali gravitasi yang digunakan dalam penelitian ini merupakan data primer yang sudah dilakukan pengolahan data. Pengolahan data dilakukan dengan mereduksi data gravitasi pengamatan sampai diperoleh nilai anomali Bouguer lengkap. Hasil interpretasi anomali medan gravitasi menunjukkan bahwa jenis batuan yang ada di bawah permukaan daerah penelitian adalah peridotit, riolit, dan basalt. Batuan dengan densitas tertinggi yaitu peridotit dengan nilai densitas 3.341 $\mathrm{gr} / \mathrm{cm}^{3}$. Hal tersebut dikarenakan adanya proses intrusi yang membentuk batuan beku jenis peridotit dan dua sesar karena terdapat dua batas zona yang memiliki perbedaan densitas yang sangat signifikan.
\end{abstract}

Kata kunci: anomali; bawah permukaan; metode gravitasi; rapat massa.

\begin{abstract}
Gravity method is one of the geophysical methods that is often used to obtain information about the subsurface through differences density of the rocks around it. Gravity anomaly data used in this study is primary data that has been processed data. Data processing is obtained by reducing gravity observation data until complete Bouguer anomaly values. The results of the interpretation of the gravity anomaly show that the types of rocks in subsurface of the study area are peridotite, rhyolite and basalt. The rock with the highest density is peridotite with a density value of $3.341 \mathrm{gr} / \mathrm{cm}^{3}$. This is due to the intrusion process to forming peridotite and there are two zones boundaries which have very significant density differences.
\end{abstract}

Keywords: anomaly; subsurface; gravity method; density.

\section{Pendahuluan}

Struktur bumi paling luar tersusun dari lapisan kerak benua dan kerak samudera. Kedua lapisan tersebut memiliki perbedaan densitas (kerapatan) yang dapat mempengaruhi medan gravitasi bumi. Salah satu metode geofisika yang dapat digunakan untuk mengidentifikasi lapisan bawah permukaan berdasarkan variasi rapat massa batuan pada suatu daerah penelitian adalah dengan menggunakan metode gravitasi.

Metode gravitasi merupakan metode ekplorasi geofisika dengan cara mengukur percepatan gravitasi di bawah permukaan bumi yang diakibatkan karena adanya 
perbedaan densitas batuan dari suatu daerah (Blakely, 1996). Metoda ini cukup baik digunakan untuk mendefinisikan daerah target spesifik untuk selanjutnya disurvei dengan metode geofisika lain yang lebih detil. Adanya suatu sumber yang berupa suatu massa (masif, lensa, atau bongkah besar) di bawah permukaan akan menyebabkan terjadinya gangguan medan gayaberat (relatif). Gangguan ini disebut sebagai anomali gayaberat. Karena perbedaan medan gayaberat ini relatif kecil maka diperlukan alat ukur yang mempunyai ketelitian yang cukup tinggi sehingga variasi medan gayaberat di permukaan bumi dapat diukur dari suatu titik observasi terhadap titik observasi lainnya. Pada penelitian ini dilakukan interpretasi dan pemodelan untuk mengetahui variasi rapat massa bawah permukaan pada daerah Bantar Karet, Jawa Barat.

\section{Prinsip Dasar Metode Gayaberat}

Prinsip dasar dari metode gayaberat/ gravitasi ini adalah menggunakan hukum gravitasi newton yang menyatakan bahwa gaya tarik menarik dua titik yang memiliki massa $m_{1}$ dan $m_{2}$ yang terpisah pada jarak $r$ maka dapat ditulis persamaan tersebut (Serway dan Jewet, 2009):

$$
\vec{F}=\gamma \frac{m_{1} m_{2}}{r^{2}} \hat{r}
$$

$\mathrm{F}$ adalah gaya yang ditimbulkan antara dua partikel yang bermassa $m_{1}$ dan $m_{2}, r$ adalah jarak antar dua partikel, $\mathrm{r}^{\wedge}$ adalah vektor satuan dari $m_{1}$ dan $m_{2}$, dan $\gamma$ adalah konstanta gravitasi universal $(6.6732 \times 10$ $11 \mathrm{~N} \mathrm{~m}^{2} / \mathrm{kg}^{2}$ ).

Percepatan benda $\mathrm{m}_{2}$ yang disebabkan oleh hadirnya benda $\mathrm{m}_{1}$ dapat ditentukan dengan membagi $\mathrm{F}$ dengan $\mathrm{m}_{2}$. Secara khusus, bila $\mathrm{m}_{1}$ adalah massa dari bumi (Me) maka percepatan dari suatu massa $\mathrm{m} 2$ di permukaan bumi adalah (Lowrie, 2007):

$$
\mathrm{g}=\frac{F}{m_{2}}=\gamma \frac{M_{e}}{R_{e}{ }^{2}}
$$

Re: jari - jari bumi.

Dalam survey gayaberat diharapkan hanya variasi densitas bawah permukaan saja, sehingga faktor - faktor lain harus dikoreksi, antara lain:

\section{Koreksi Pasang Surut (Tide Correction)}

Koreksi pasang surut disebabkan karena adanya pengaruh dari pasang surut. Koreksi tersebut dilakukan untuk menghilangkan efek gravitasi benda-benda di luar bumi seperti matahari dan bulan. Besarnya perubahan yang disebabkan ini bervariasi terhadap lintang, waktu bulanan, waktu tahunan (Untung, 2001).

\section{Koreksi Apungan (Drift Correction)}

Koreksi apungan terjadi karena adanya perbedaan pembacaan percepatan gravitasi pada stasiun yang sama akan tetapi waktu yang berbeda. Untuk menghilangkan efek ini, akusisi data didesain dalam suatu rangkaian tertutup, sehingga besar penyimpangan tersebut dapat diketahui dan diasumsikan linier pada selang waktu tertentu (t) (Reynolds, 1997). Persamaan untuk koreksi apungan dapat dilihat pada persamaan berikut ini (Reynolds, 1997):

$$
\text { drift }=\frac{\left(\mathrm{g}_{n}-\mathrm{g}_{0}\right)}{\left(t_{n}-t_{0}\right)}\left(t_{n}-t_{0}\right)
$$

$\mathrm{t}_{\mathrm{n}}$ adalah waktu ke-n; $\mathrm{t}_{0}$ waktu pada pembacaan pertama; $g_{n}$ adalah hasil bacaan percepatan gravitasi ke-n; $\mathrm{g}_{0}$ adalah hasil bacaan percepatan gravitasi yang pertama.

\section{Koreksi Lintang (Latitude Correction)}

Spheroid referensi ( $\mathrm{g}_{\text {lintang }}$ ) diberikan oleh persamaan GRS67 (Telford et al., 1990):

$$
\begin{aligned}
\mathrm{g}_{\text {lintang }}= & 978031.846\left(1+0.005278895 \sin ^{2} \Phi+\right. \\
& \left.0.000023462 \sin ^{4} \Phi\right)
\end{aligned}
$$


Keterangan;

$\Phi \quad$ : sudut lintang

$\mathrm{g}_{\text {lintang }}$ : gaya berat normal pada lintang $\Phi$ (mGal)

\section{Koreksi Udara Bebas (Free Air Correction)}

Koreksi udara bebas merupakan koreksi yang dilakukan karena adanya pengaruh ketinggian terhadap medan gravitasi bumi, Besarnya faktor koreksi (Free Air Correction/ FAC) untuk daerah ekuator hingga lintang $45^{\circ}$ atau $-45^{\circ}$ adalah $-0,3085$ $\mathrm{mGal} / \mathrm{m}$. Sehinga besarnya anomali pada posisi tersebut menjadi FAA (Free Air Anomaly) (Reynolds, 1997), yaitu :

$$
\text { FAA }(\mathrm{R}+\mathrm{h})=\mathrm{g}_{\text {obs }}-\mathrm{g}(\mathrm{R})+0.3085 \mathrm{~h}
$$

Dengan:

FAA : Free Air Correction

gobs : percepatan gravitasi observasi

h : Ketinggian yang telah dikoreksi

$\mathrm{g}(\mathrm{R}) \quad$ :Nilai percepatan gravitasi yang telah dikoreksi lintang.

\section{Koreksi Bouguer (Bouguer Correction/BC)}

Koreksi Bouguer dilakukan dengan menggunakan pendekatan benda berupa slab tak berhingga yang besarnya diberikan oleh persamaan (Kearey et al., 2002):

$$
\mathrm{BC}=2 \pi G \rho h
$$

\section{Koreksi Topografi (Terrain Correction)}

Koreksi tersebut dikarenakan adanya akibat dari pendekatan Bouguer. Hal ini yang bersifat mengurangi dalam SBA (Simple Bouguer Anomaly), sehingga dalam penerapan koreksi medan, efek gravitasi blok-blok topografi yang tidak rata harus ditambahkan terhadap SBA. Dengan demikian anomali gaya berat menjadi (Blakely, 1996):

$\mathrm{CBA}=\mathrm{g}_{\mathrm{obs}}-\mathrm{g} \phi+0,3085 \mathrm{~h}-\mathrm{BC}+\mathrm{TC}(7)$ dengan CBA adalah Complete Bouguer Anomaly dan TC adalah Terrain Correction. Untuk menghitung Terrain Correction (TC) dapat digunakan persamaan (Reynolds, 1997):

$$
\begin{aligned}
T C= & 0,04191 \frac{\rho}{n}\left(r_{2}-r_{1}+\sqrt{r_{1}^{2}+z^{2}}-\right. \\
& \left.\sqrt{r_{2}^{2}+z^{2}}\right)
\end{aligned}
$$

\section{Metode Penelitian}

Data yang diperoleh dalam akuisisi (data mentah) diteruskan ke processing data kemudian diolah dengan menggunakan beberapa software yaitu Microsoft Excel untuk mendapatkan nilai CBA lalu dengan menggunakan program Surfer 10 dibuat peta CBA (Complete Bouguer Anomaly) untuk membuat peta anomali regional dan residual. Selanjutnya dilakukan Moving Average untuk mengetahui nilai densitas dari suatu daerah tersebut.

\section{Hasil dan Pembahasan}

Variasi densitas bawah permukaan relatif kecil sehingga diperlukan alat dengan ketelitian yang cukup tinggi sehingga dalam proses akuisisi datanya digunakan Gravimeter. Jenis gravimeter yang digunakan untuk pengambilan data di lapangan adalah Gravimeter Autograv CG5. Gravimeter jenis ini tidak menggunakan skala analog tetapi sudah dilengkapi dengan koreksi percepatan gravitasi observasi absolut dan sehingga nilai yang dihasilkan tidak berupa alloid.

Nilai percepatan gravitasi di setiap tempat di permukaan bumi dipengaruhi oleh banyak faktor, antara lain gaya tarik menarik benda-benda angkasa, ketinggian, topografi di sekitar titik pengukuran dan lintang. Oleh sebab itu, nilai bacaan pada alat berupa nilai percepatan gravitasi relatif sehingga untuk mendapatkan nilai percepatan gravitasi yang sebenarnya dilakukan koreksi-koreksi. Koreksi-koreksi 
tersebut antara lain Koreksi Pasang Surut, Koreksi Drift, Koreksi Lintang, Koreksi Udara Bebas, dan Koreksi Bouguer. Koreksi Pasang Surut dilakukan akibat adanya pengaruh gaya tarik benda-benda lain, misalnya bulan dan matahari dan juga karena adanya rotasi bumi. Setelah data tersebut dikoreksi maka didapatkan nilai
Complete Bouguer anomaly (CBA). Nilai CBA merupakan akumulasi percepatan gravitasi dari titik observasi sampai kedalaman yang tidak diketahui (relatif pada basement). Berdasarkan nilai CBA tersebut maka dihasilkan peta CBA, seperti pada Gambar 1, dengan menggunakan software Surfer.

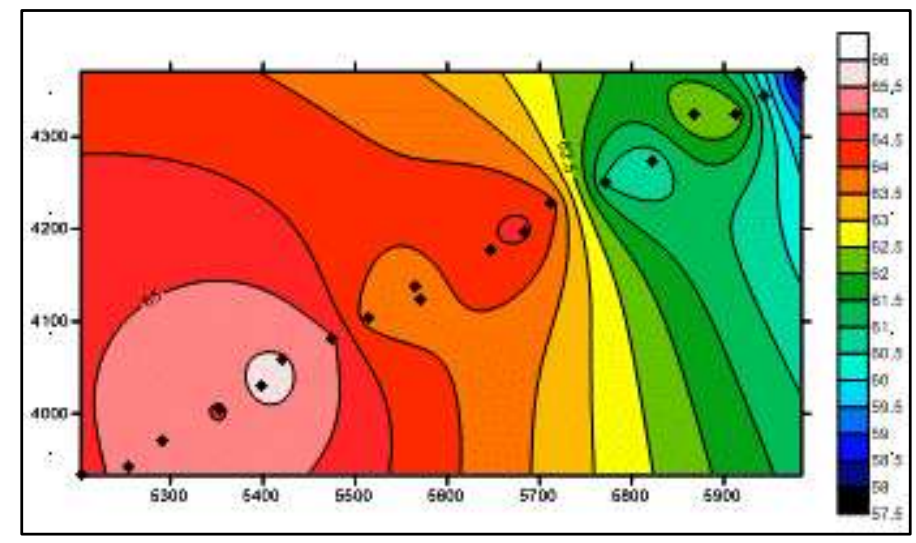

Gambar 1. Peta anomali Bouguer lengkap.

Metode gravitasi dalam hal ini digunakan untuk keperluan mengetahui kondisi bawah permukaan berdasarkan sebaran nilai variasi rapat massa sehingga yang dimodelkan adalah peta anomali residual. Anomali residual cukup dangkal dibandingkan dengan anomali regional sebab anomali residual berkaitan dengan frekuensi tinggi sehingga yang dihasilkan adalah peta anomali yang dekat dengan permukaan (source). Sebaliknya, anomali regional berkaitan dengan frekuensi rendah sehingga memiliki kedalaman yang lebih dalam dibanding residual. Hal ini disebabkan oleh adanya atenuasi gelombang dimana frekuensi akan terus melemah seiring pertambahan jarak dan waktu (Gambar 2).

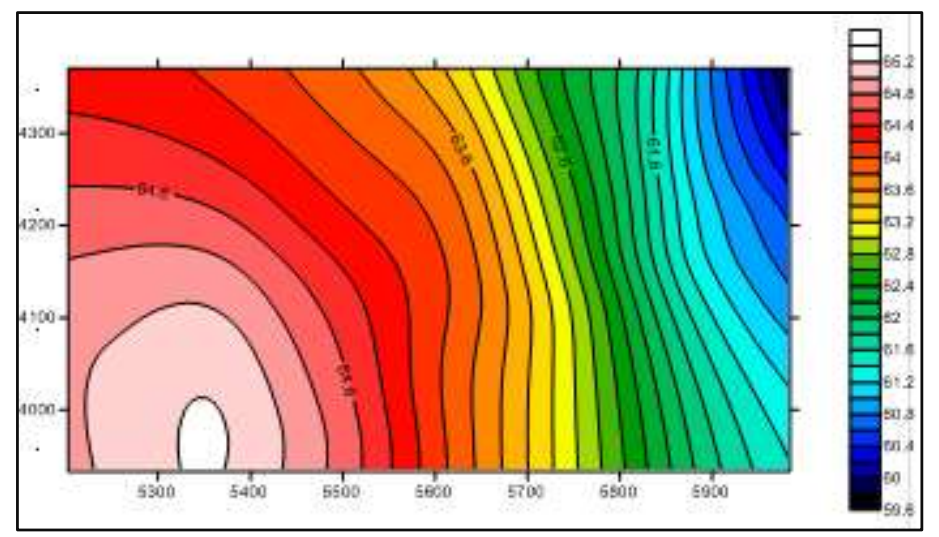

Gambar 2. Peta Anomali Regional.

Untuk mendapatkan anomali residual perlu dilakukan pemisahan (filtering) CBA menjadi anomali regional dan anomali residual. Banyak metode filtering yang dapat digunakan untuk memisakan anomali tersebut. Salah satunya yaitu Moving 
Average dan Second Vertical Derrivative (SVD). Namun, pada kasus ini metode filtering yang digunakan adalah metode Moving Average. Sebelum dilakukan pemisahan, peta CBA perlu dianalisis spektral. Analisis spektral bertujuan untuk estimasi kedalaman dan menentukan jumlah maksimal window yang akan digunakan pada proses filterasi (pemisahan). Peta CBA yang telah diiris berisi spasi dan nilai CBA. Karena analisis spektral memanfaatkan analisis fourier maka pertambahan spasi yang digunakan tetap. Sehingga dibutuhkan spasi baru dan CBA baru yang bergantung pada nilai spasi dan CBA yang didapatkan dari hasil slice.
Spasi baru dan CBA baru tersebut diolah dengan NUMERI.EXE. Software ini menggunakan prinsip Tranformasi Fourier. Sehingga data yang sebelumnya dalam domain waktu dapat ditransfomasi dalam domain frekuensi. Hasil yang didapatkan berupa nilai real dan imajiner serta frekuensi. Nilai tersebut digunakan untuk mendapatkan nilai amplitudo (A), bilangan gelombang (k), dan logaritma natural amplitudo (ln A). Korelasi antara k dan $\ln$ A menghasilkan grafik yang memperlihatkan nilai gradien dan nilai konstanta untuk regional dan residual. Sehingga dapat dihitung nilai cut off dan window (Gambar 3).

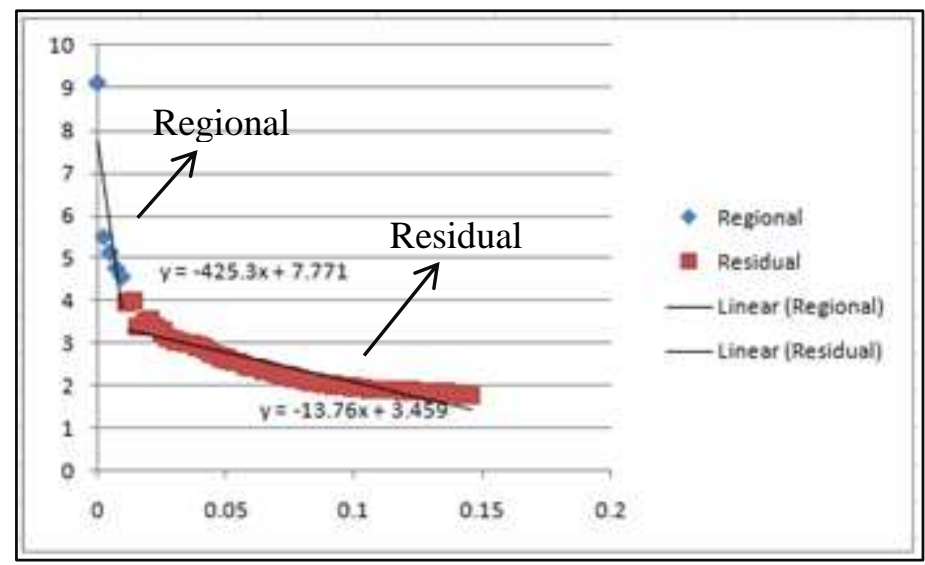

Gambar 3. Korelasi antara k dan $\ln \mathrm{A}$

Window yang dihasilkan merupakan nilai maksimal yang akan digunakan pada proses filterasi Moving Average. Perlu diperhatikan bahwa semakin kecil nilai window maka akan semakin mirip dengan data asli. Begitupun sebaliknya, semakin besar nilai window maka akan semakin banyak data yang tersamarkan. Metode Moving Average merupakan metode low pass filter, yaitu mampu meloloskan frekuensi rendah dan memfilter frekuensi tinggi. Sehingga peta yang dihasilkan berupa peta anomali regional. Karena yang dimodelkan adalah peta residual maka dilakukan pengurangan peta CBA dengan peta anomali regional untuk memperoleh peta anomali residual. Peta anomali residual tersebut dapat dijadikan sebagai analisis awal terhadap adanya sesar atau intrusi. Pada peta tersebut diperlihatkan daerah yang memiliki nilai percepatan gravitasi yang tinggi dan daerah yang memiliki percepatan gravitasi yang rendah. Secara teori, sesar kemungkinan terdapat pada batas zona dengan nilai densitas tinggi dan dengan nilai densitas rendah (Gambar 4). 


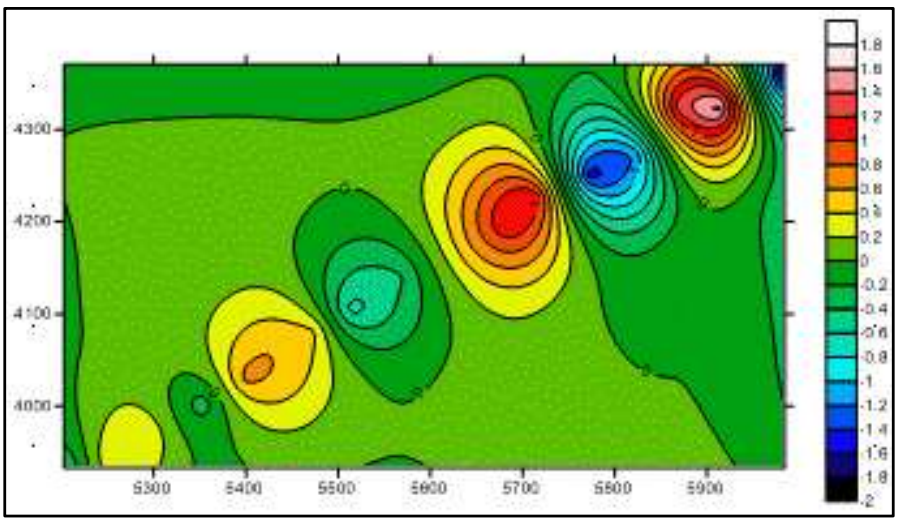

Gambar 4. Peta Anomali Residual

Untuk lebih mendetailkan analisis mengenai sesar tersebut, peta anomali residual tersebut kemudian diiris dan dimodelkan pada software Grav2dc. Hal ini bertujuan untuk mengetahui model variasi densitas batuan yang ada di bawah permukaan sepanjang daerah yang telah diiris. Nilai yang terdapat pada body dalam model Grav2dc bukanlah nilai densitas melainkan nilai kontras densitas. Nilai densitas batuan tersebut diperoleh dengan mengurangkan densitas batuan dominan dengan nilai kontras densitas pada body dalam model tersebut. Untuk model lintasan panjang sumbu x yaitu \pm 800 meter dengan kedalaman 200 meter.

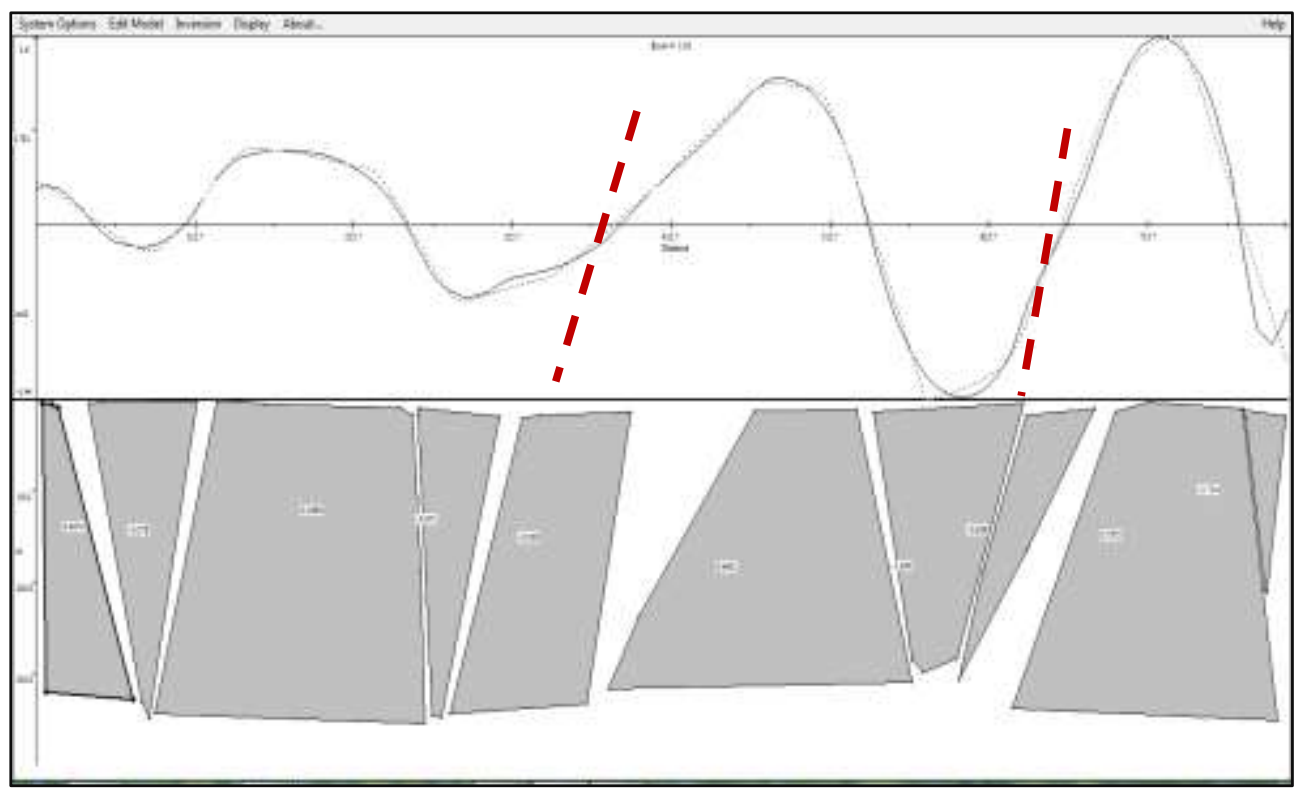

Gambar 5. Model penampang bawah permukaan.

Berdasarkan hasil proses matching didapatkan kontras densitas yang ditunjukkan pada Gambar 5. Selanjutnya nilai kontras densitas tersebut kemudian dikurangkan dengan nilai densitas andesit sebesar 2,67 $\mathrm{gr} / \mathrm{cm}^{3}$ sehingga didapatkan variasi nilai rapat massa batuan pada daerah tersebut (Tabel 1).

Berdasarkan pemodelan bawah permukaan daerah penelitian, batuan yang dominan menjadi sumber anomali adalah peridotit, riolit, dan basalt (Telford et al., 1990). Hal 
tersebut terjadi karena adanya proses intrusi sehingga membentuk batuan beku jenis peridotit dan terdapat dua sesar karena terdapat dua batas zona yang memiliki perbedaan densitas yang sangat signifikan (Gambar 5). Satuan litologi daerah penelitian terdiri atas satuan tuf laminasi, satuan breksi vulkanik, satuan lava andesit, satuan tuf lapilli, satuan tuf dan satuan intrusi dasit (Febriyana dkk., 2014).

Tabel 1. Nilai kontras densitas dan densitas hasil pengukuran.

\begin{tabular}{ccc}
\hline $\begin{array}{c}\text { Kontras } \\
\text { densitas } \\
\left(\mathbf{g r} / \mathbf{c m}^{\mathbf{3}}\right)\end{array}$ & $\begin{array}{c}\text { Densitas hasil } \\
\text { pengolahan } \\
\left(\mathbf{g r} / \mathbf{c m}^{\mathbf{3}}\right)\end{array}$ & $\begin{array}{c}\text { Jenis batuan } \\
\text { (Telford et al., } \\
\mathbf{1 9 9 0})\end{array}$ \\
\hline 0,4574 & 2,2126 & Clay \\
\hline$-0,378$ & 3,048 & Basalt \\
\hline 0,2686 & 2,4014 & Riolit \\
\hline$-0,671$ & 3,341 & peridotit \\
\hline$-0,3$ & 2,97 & peridotit \\
\hline 0,6451 & 2,0249 & Sand \\
\hline$-0,16$ & 2,83 & Basalt \\
\hline$-0,639$ & 3,309 & peridotit \\
\hline 0,7873 & 1,8827 & Sand \\
\hline
\end{tabular}

\section{Kesimpulan}

Berdasarkan penelitian tersebut dapat disimpulkan bahwa Nilai Complete Bouguer Anomaly (CBA) daerah Bantar Karet, Jawa Barat berkisar antara 57,5 - 66 $\mathrm{mGal}$. Anomali rendah terletak di bagian timur, timurlaut dan utara. Anomali tinggi terletak di bagian baratdaya dan tenggara. Nilai anomali rendah berasosiasi dengan nilai kontras rapat massa batuan yang kecil sedangkan nilai anomali tinggi berasosiasi dengan nilai kontras rapat massa batuan yang tinggi. Perubahan nilai anomali rendah ke tinggi yang sangat signifikan terlihat di bagian timur. Perubahan ini disebabkan oleh perubahan nilai kontras rapat massa batuan yang terjadi akibat tebalnya sedimentasi.

Berdasarkan interpretasi kuantitatif, diperoleh variasi nilai rapat massa batuan yang mengindikasikan daerah tersebut dominan batuan peridotit, riolit, dan basalt.
Batuan dengan densitas tertinggi yaitu peridotit dengan nilai densitas 3,341 $\mathrm{gr} / \mathrm{cm}^{3}$. Hal tersebut terjadi karena adanya proses intrusi sehingga membentuk batuan beku jenis peridotit dan terdapat dua sesar karena terdapat dua batas zona yang memiliki perbedaan densitas yang sangat signifikan.

\section{Daftar Pustaka}

Blakely, R.J., 1996, Potential theory in gravity and magnetic applications: Cambridge University Press, New York, $441 \mathrm{p}$.

Febriyana, R.D, Aribowo,Y, Widiarso. D.A, 2014, Geologi dan alterasi hidrotermal Daerah Bantar Karet dan sekitarnya Kecamatan Nanggung, Kabupaten Bogor, Provinsi Jawa Barat, Geological Engineering E-Journal. Vol. 6(1), 218-232.

Kearey, P., Keith, A.K., Vine, F.J. 2009. Global Tectonics. New Jersey: WileyBlackwell.

Lowrie, W. 2007. Fundamental of Geophysics. Cambridge University Press. Cambridge, United Kingdom.

Reynold, J. M., 1997, An Introduction to Applied and Environmental Geophysics, John Wiley and Sons Inc., England.

Serway, Raimond A. dan Jhon W. Jewet, Jr., 2009. Fisika untuk Sains dan Teknik. Jakarta: Salemba Teknika.

Telford, W. M., Geldart, L. P., Sheriff, R. E., and Keys. D. A., 1990, Applied Geophysics, Cambridge University Press, Cambridge.

Untung. M., 2001, Dasar - Dasar Magnet dan Gayaberat Serta Beberapa Penerapannya, Himpunan Ahli Geofisika Indonesia (HAGI), Jakarta. 